\title{
Phosphorus-Containing Polystyrene Derivatives as Flame Resistance
}

\author{
Junji FuruKaWA, Eiichi KobaYASHI, and Tadahiro WAKuI* \\ Department of Industrial Chemistry, Science University of Tokyo, \\ Yamazaki, Noda 278, Japan.
}

(Received September 8, 1979)

\begin{abstract}
The synthesis of monomers containing phosphorus, their polymerization or copolymerization and the flame resistance of these polymers were investigated. It was found that diethyl-( $p$-vinylphenyl) phosphate (PO) and diethyl- ( $p$-vinylphenyl) thiophosphate (PS) could be prepared readily from the sodium salt of $p$-vinylphenol. PO and PS underwent polymerization and copolymerization with methyl methacrylate (MMA), styrene (ST), methyl acrylate (MA), and maleic anhydride (Manh) to produce glassy and transparent solids, that are flame resistant. The copolymers of PO-Manh and PS-Manh were found to be alternating. The flame resistance was better with the polymers containing phosphorus-oxygen than phosphorus-sulfur. However, the flame resistance of the copolymers was not always higher than that of mixture of homopolymers. An aggregation state of phosphorus groups may effectuate high flame resistance of polymer mass.
\end{abstract}

KEY WORDS Diethyl-( $p$-vinylphenyl) Phosphate / Diethyl-( $p$-vinylphenyl) Thiophosphate / $p$-Trimethylsilyloxystyrene / Copolymerization / Monomer Reactivity Ratio / $Q-e$ Value / Alternating Copolymerization / Phosphorus Containing Polymer / Flame Resistance /

The production of flame resistant materials is one of several important problems and there is very extensive literature on this subject. ${ }^{1}$ The application of organophosphorus polymers, either by their simple addition to materials or as substances chemically linked to them, or absorbed on them, often offers a solution to this problem. It is well known that di-(2-chloroethyl)-vinyl phosphate ${ }^{2,3}$ and the allyl or alkyl ester of the phoshorus acid ${ }^{4-7}$ are generally utilized in copolymerization with the unsaturated polyester in order to obtain flame-proof polyester resins. These self-extinguishing characteristics are even retained in copolymers produced by copolymerization with other compatible monomers. ${ }^{8.9}$ However, a comparison on the degree of flame resistance between the simple addition of phosphoruscontaining polymers to the materials and the substances chemically linked to them is not well known.

The purpose of this study is to investigate the synthesis of the dialkylester of $p$-hydroxystyrene containing phosphorus-oxygen and phosphorussulfur, their polymerization and copolymerization characteristics, and then the difference in flame

* Research Laboratory, Maruzen Oil Co., Satte-machi, Kitakatsushika-gun, Saitama 340-01, Japan. resistance between the blend of phosphoruscontaining polymer to materials and the copolymers. $p$-Trimethylsilyloxystyrene was also synthesized.

\section{EXPERIMENTAL}

\section{Material}

Toluene used as the solvent was purified in the usual manner. Styrene (ST), methyl methacrylate (MMA), and methyl acrylate (MA) were purified by distillation under a nitrogen atmosphere just before use. Maleic anhydride (Manh) was recrystallized from a chloroform solution. Azobisisobutyronitrile (AIBN) was used without further purification. $\mathrm{BF}_{3} \mathrm{OEt}_{2}$ was of reagent grade and used without further purification. $p$-Hydroxystyrene was recrystallized from a hexane solution, $\mathrm{mp} 71-72^{\circ} \mathrm{C}^{10}$

\section{Preparation of Monomers}

Diethyl-( p-vinylphenyl) Phosphate. $30 \mathrm{~g} \quad(0.25$ mol) of $p$-hydroxystyrene in $100 \mathrm{ml}$ of dry ether was added slowly with stirring to the suspension of sodium hydride $6.0 \mathrm{~g}(0.25 \mathrm{~mol})$ in $150 \mathrm{ml}$ of dry ether. The mixture was then stirred at room temperature for another $1 \mathrm{~h}$. The suspension of sodium $p$ - 
vinylphenoxide so obtained was cooled to $0^{\circ} \mathrm{C}$ and a solution of diethyl phosphorochloridate $43.1 \mathrm{~g}(0.25$ $\mathrm{mol}$ ) in $50 \mathrm{ml}$ of dry ether added slowly with stirring. The total content of the mixture was stirred for $5 \mathrm{~h}$ to ensure a complete reaction. Water was then added and the ether layer was washed successively with a $2 \%$ aqueous solution of sodium hydroxide, then with water, and dried over $\mathrm{Na}_{2} \mathrm{SO}_{4}$ and evaporated. The residue was distilled at $102-104^{\circ} \mathrm{C}(0.1 \mathrm{mmHg}$, giving diethyl-( $p$-vinylphenyl) phosphate (PO) $40.3 \mathrm{~g}(63.0 \%$ yield $)$ as a colorless liquid, $n_{\mathrm{D}}^{20} 1.5028$. (Found: C, 56.25\%; H, 6.64\%. Calcd: C, 55.98\%; H, $6.33 \%$.)

The IR spectrum of PO (liquid film) is shown in Figure 1. It was found that there are an absorption due to vinyl group at $1615 \mathrm{~cm}^{-1}$, two absorptions due to $\mathrm{P}-\mathrm{O}$-aryl at $1220,1170 \mathrm{~cm}^{-1}$, two absorptions due to $\mathrm{P}-\mathrm{O}$-alkyl at 1170,1040 , and an absorption due to $\mathrm{P}=\mathrm{O}$ at $1310 \mathrm{~cm}^{-1}$. The NMR spectrum $\left(\mathrm{CDCl}_{3}\right)$ of $\mathrm{PO}$ is illustrated in Figure 2, exhibiting a triplet signal due to six protons of the two methyl groups of $-\mathrm{O}-\mathrm{CH}_{2}-\mathrm{CH}_{3}$ at $\delta 1.36 \mathrm{ppm}$ $(J=7 \mathrm{~Hz})$, a double quartet signal ${ }^{11}$ due to four protons of the two methylene groups of $\mathrm{CH}_{2} \mathrm{CH}_{3}$ at $\delta 4.20 \mathrm{ppm}(J=7 \mathrm{~Hz})$, three double doublet signal due to three protons of the vinyl group at $\delta 5.20 \mathrm{ppm}$ $(J=11 \mathrm{~Hz}), 5.63(J=17.4 \mathrm{~Hz})$, and $6.66(J=11 \mathrm{~Hz})$, respectively, and an $\mathrm{AB}$ quartet signal due to four protons of aromatic group at $\delta 7.30 \mathrm{ppm}(J=8 \mathrm{~Hz})$.

Diethyl-( p-vinylphenyl) Thiophosphate. Diethylthiophosphorochloridate, $47.1 \mathrm{~g}(0.25 \mathrm{~mol})$ in $50 \mathrm{ml}$ of dry ether was added slowly with stirring to the suspension of sodium $p$-vinylphenoxide prepared as described above from $p$-vinylphenol $30 \mathrm{~g}(0.25 \mathrm{~mol})$ and sodium hydride $6.0 \mathrm{~g}(0.25 \mathrm{~mol})$ in $150 \mathrm{ml}$ of dry ether. The mixture was stirred at room temperature for another $5 \mathrm{~h}$, and then was worked up as described for diethyl-( $p$-vinylphenyl) phosphate. The residual diethyl-( $p$-vinylphenyl) thiophosphate (PS) $39.5 \mathrm{~g}$ $(58.0 \%$ yield $)$ was distilled at $105-106^{\circ} \mathrm{C}(0.05$ $\mathrm{mmHg}$, as a colorless liquid, $n_{\mathrm{D}}^{20} 1.5297$. (Found: $\mathrm{C}$, $52.94 \%$; H, 6.25\%. Calcd: C, 52.38\%; H, 6.24\%.)

The IR spectrum of PS (liquid film) is shown in Figure 1. Similar spectral data were obtained for PS as detailed in PO, showing absorptions at 1610 (vinyl group), 1200, 1160, (P-O-aryl), 1160, 1015 (P-Oalkyl), $710\left(\mathrm{P}=\mathrm{S}\right.$, weak) $\mathrm{cm}^{-1}$. The NMR spectrum $\left(\mathrm{CDCl}_{3}\right)$ exhibited similar spectral data as detailed in $\mathrm{PO}$, except for a little difference in chemical shift (Figure 2).
p-Trimethylsilyloxystyrene. Trimethylsilyl chloride $27.7 \mathrm{~g}(0.26 \mathrm{~mol})$ was added slowly to the stirred solution of $p$-hydroxystyrene $30.6 \mathrm{~g}(0.26$ $\mathrm{mol})$ and dry pyridine $20.0 \mathrm{~g}(0.26 \mathrm{~mol})$ in $200 \mathrm{ml}$ of dry ether. The mixture was stirred at room temperature for another $5 \mathrm{~h}$. Water was then added and the ether layer was washed with a $2 \%$ aqueous solution of sodium hydroxide, and then with water, and dried over $\mathrm{Na}_{2} \mathrm{SO}_{4}$ and evaporated. The residue was distilled at $47-48^{\circ} \mathrm{C}(0.08 \mathrm{mmHg})$, giving $p$ trimethylsilyloxystyrene (TS) $34.9 \mathrm{~g}(70.0 \%$ yield) as a colorless liquid. (Found: C, $68.72 \% ; \mathrm{H}, 8.33 \%$. Calcd: C, $68.45 \%$; H, $8.06 \%$.)

The IR spectrum of TS (liquid film) is shown in Figure 1 and shows absorption due to a vinyl group at $1610 \mathrm{~cm}^{-1}$, two absorptions due to $-\mathrm{Si}\left(\mathrm{CH}_{3}\right)_{3}$ at $1250,840 \mathrm{~cm}^{-1}$. The NMR spectrum $\left(\mathrm{CDCl}_{3}\right)$ of TS is illustrated in Figure 2 and exhibits a singlet signal due to nine protons of the three methyl groups of $-\mathrm{Si}\left(\mathrm{CH}_{3}\right)_{3}$ at $\delta 0.27 \mathrm{ppm}$, three double doublet signal due to three protons of the vinyl groups at $\delta 5.17$ $(J=11 \mathrm{~Hz}), \quad 5.60 \quad(J=17 \mathrm{~Hz}), \quad$ and $6.75 \mathrm{ppm}$ $(J=11 \mathrm{~Hz})$, respectively, and an AB quartet signal due to four protons of aromatic group at $\delta 7.07 \mathrm{ppm}$ $(J=9 \mathrm{~Hz})$.

\section{Polymerization}

Some typical runs are described below.

Free Radical Polymerization. $10 \mathrm{mg}(0.06 \mathrm{mmol})$ of initiator (AIBN) was put into a dry glass ampoule, evacuated and flushed with a pure nitrogen gas, and subsequently $1.36 \mathrm{~g}(5.3 \mathrm{mmol})$ of $\mathrm{PO}$ and $2.0 \mathrm{ml}$ of toluene were introduced into this under an atmosphere of nitrogen. The glass ampoule was dipped in a bath cooled at $-78^{\circ} \mathrm{C}$, and then sealed. Polymerization was carried out at $60^{\circ} \mathrm{C}$ (see Table I). After $7 \mathrm{~h}$, the ampoule was taken out, cooled, and then opened. The content of the ampoule was poured into a large excess of methanol. The coagulated polymer was washed with a large amount of methanol, dried in vacuo and then weighed. Yield $0.5 \mathrm{~g}(37.0 \%)$.

Cationic Polymerization. $1.36 \mathrm{~g}(5.3 \mathrm{mmol})$ of $\mathrm{PO}$ and $10 \mathrm{ml}$ of toluene were put into a dry $10 \mathrm{ml}$ flask, which was evacuated and flushed with a pure nitrogen gas, and then dipped into a bath cooled at $-30^{\circ} \mathrm{C}$. $1.0 \mathrm{ml}$ of the toluene solution containing $0.4 \mathrm{~g}(2.7 \mathrm{mmol}) / 100 \mathrm{ml}$ of boron trifluoride etherate was injected through the three-way cock into the flask, and the mixture was allowed to stand for $1 \mathrm{~h}$ at 
Phosphorus-Containing Polymers as Flame Resistance
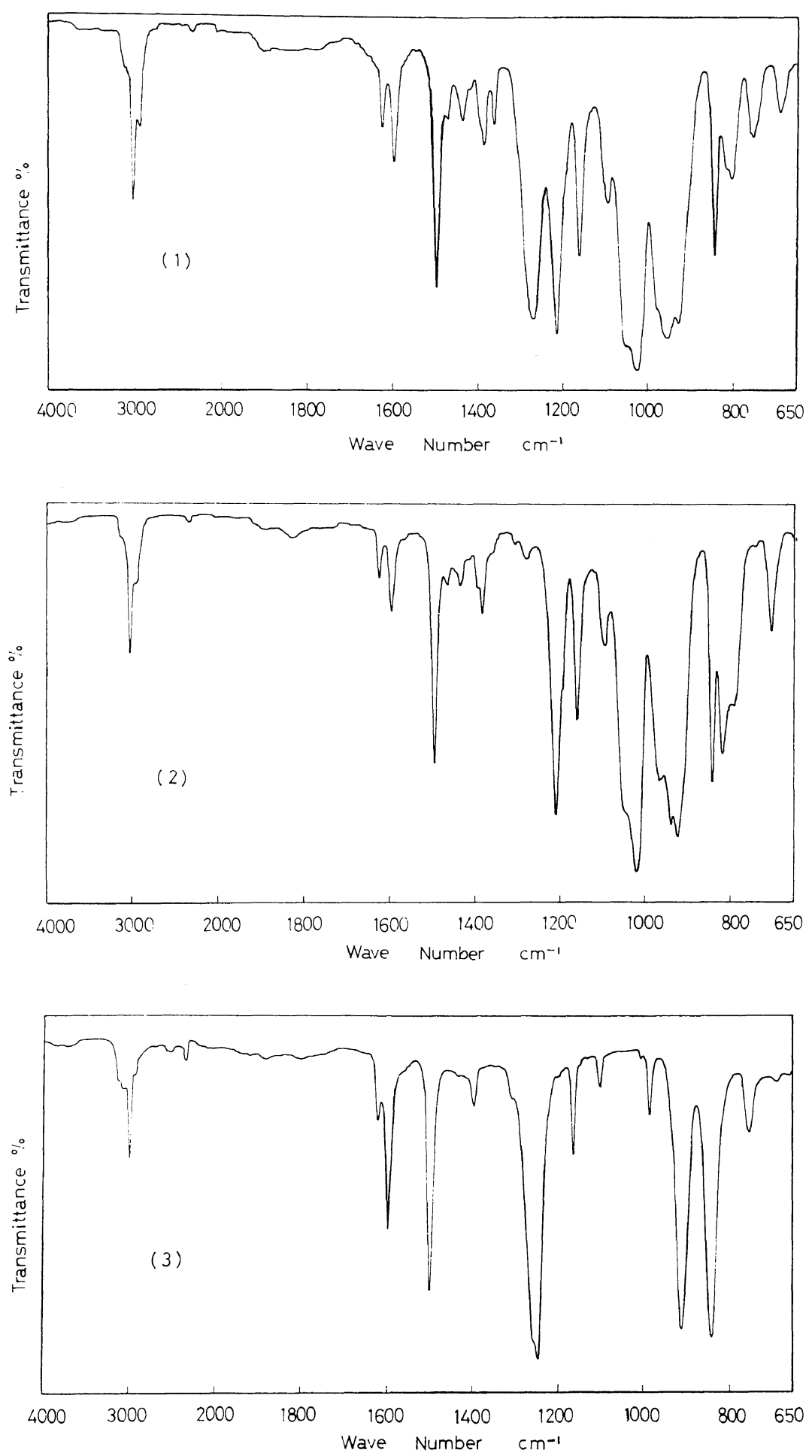

Figure 1. Infrared spectra of Monomer: (1), diethyl-( $p$-vinylphenyl) phosphate (PO); (2), diethyl-( $p$ vinylphenyl) thiophosphate (PS); (3), p-trimethylsilyloxystyrene (TS). 

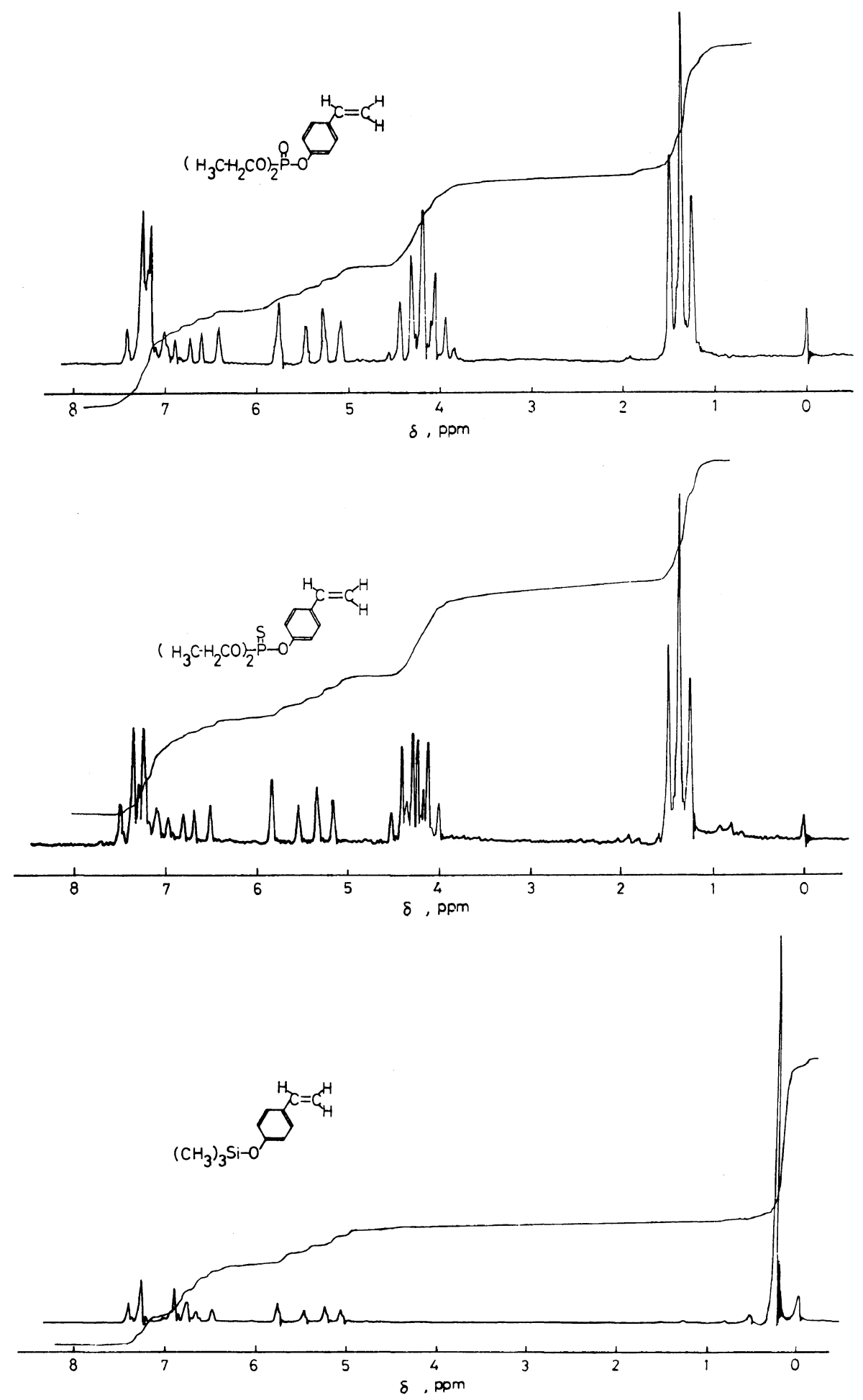

Figure 2. NMR spectra of monomer. 
Phosphorus-Containing Polymers as Flame Resistance

Table I. Polymerization of PO, PS, and TS

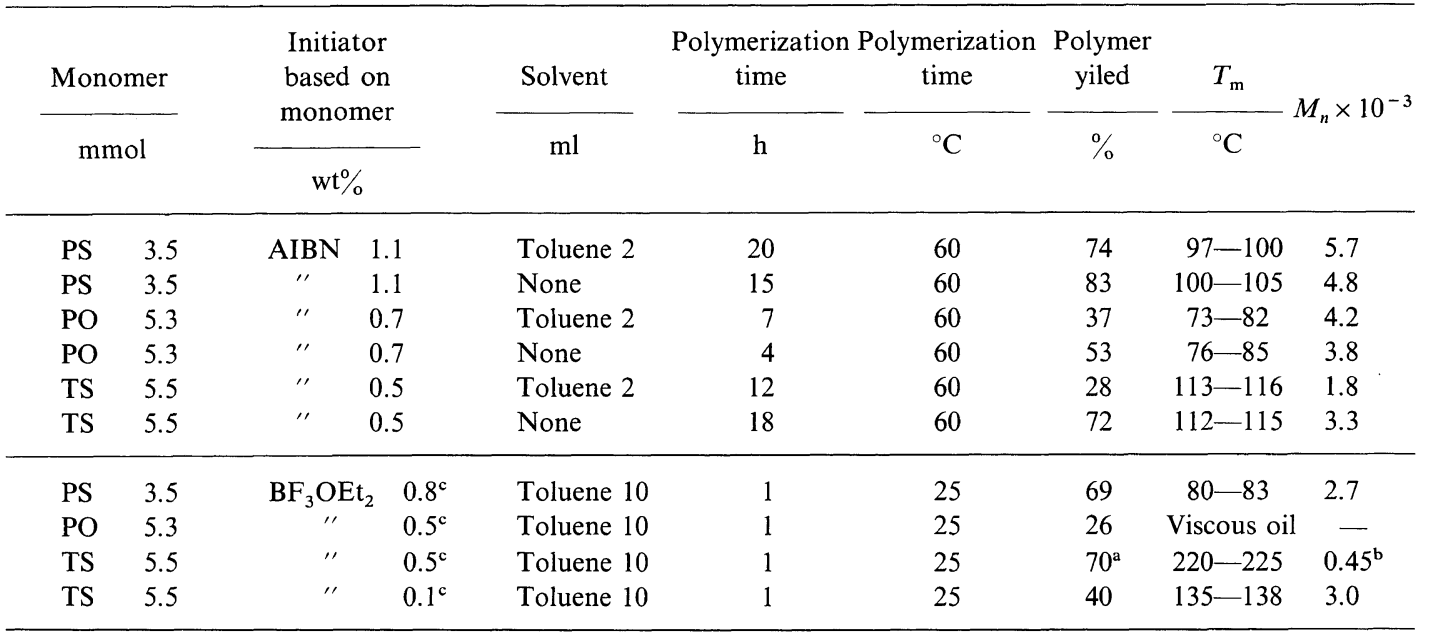

a Poly(hydroxystyrene).

b $[\eta], \mathrm{dl} \mathrm{g}{ }^{-1}$ at $30^{\circ} \mathrm{C}$ in DMF $\left([\eta]_{30^{\circ} \mathrm{C}}^{\text {acetone }}=0.50 \mathrm{dlg}{ }^{-1}\right)$. Refer to M. Kato, J. Polym. Sci., A-1, 7, 2405 (1969). ${ }^{12}$

c $\mathrm{mol} \%$ based on monomer.

$25^{\circ} \mathrm{C}$ under an atmosphere of nitrogen. The contents were treated in almost the same way as in the free radical polymerization. Yield $0.35 \mathrm{~g}(26.0 \%)$.

Copolymerization. $1.36 \mathrm{~g}(5.3 \mathrm{mmol})$ of $\mathrm{PO}, 0.55 \mathrm{~g}$
(5.3 mmol) of styrene (ST), $4.0 \mathrm{ml}$ of toluene and $20.0 \mathrm{mg}$ of AIBN were put into an ampoule under an atmosphere of nitrogen (see Table II). The ampoule was sealed according to the procedure employed in the free radical polymerization. Copolymerization

Table II. Copolymerization of PS, PO, and TS with MMA, ST, Manh and MA at $60^{\circ} \mathrm{C}^{\mathrm{a}}$

\begin{tabular}{|c|c|c|c|c|c|}
\hline \multirow[t]{2}{*}{$\begin{array}{l}\text { Monomer } \\
\text { molar ratio }\end{array}$} & \multirow{2}{*}{$\begin{array}{c}\begin{array}{c}\text { AIBN } \\
\text { based on } \\
\text { monomer }\end{array} \\
w_{t} \%\end{array}$} & \multirow{2}{*}{$\frac{\begin{array}{c}\text { Polymerization } \\
\text { time }\end{array}}{\mathrm{h}}$} & \multirow{2}{*}{$\begin{array}{c}\begin{array}{c}\text { Polymer } \\
\text { yield }\end{array} \\
\%\end{array}$} & \multirow{2}{*}{$\frac{T_{\mathrm{m}}}{{ }^{\circ} \mathrm{C}}$} & \multirow[t]{2}{*}{$M_{n} \times 10^{-3}$} \\
\hline & & & & & \\
\hline $\mathrm{PS} / \mathrm{MMA}=1^{\mathrm{b}}$ & 1.5 & 15 & 97 & $112-115$ & 1.2 \\
\hline $\mathrm{PS} / \mathrm{ST}=1^{\mathrm{b}}$ & 1.5 & 15 & 97 & $110-115$ & 5.2 \\
\hline $\mathrm{PS} / \mathrm{Manh}=1^{\mathrm{b}}$ & 0.4 & 3 & 48 & $168-175$ & $0.68^{\mathrm{e}}$ \\
\hline $\mathrm{PS} / \mathrm{MA}=1^{\mathrm{b}}$ & 0.4 & 10 & 76 & $87-93$ & 1.8 \\
\hline $\mathrm{PO} / \mathrm{MMA}=1^{\mathrm{c}}$ & 1.1 & 8 & 73 & $110-115$ & 1.2 \\
\hline $\mathrm{PO} / \mathrm{ST}=1^{\mathrm{c}}$ & 1.1 & 8 & 62 & $115-118$ & 3.2 \\
\hline $\mathrm{PO} / \mathrm{Manh}=1^{\mathrm{c}}$ & 0.5 & 3 & 57 & $163-172$ & $0.52^{\mathrm{e}}$ \\
\hline $\mathrm{PO} / \mathrm{MA}=1^{\mathrm{c}}$ & 0.6 & 10 & 42 & $96-110$ & 2.2 \\
\hline $\mathrm{TS} / \mathrm{MMA}=1^{\mathrm{d}}$ & 0.3 & 17 & 46 & $158-162$ & 2.0 \\
\hline $\mathrm{TS} / \mathrm{ST}=1^{\mathrm{d}}$ & 0.3 & 50 & 25 & $145-150$ & 4.0 \\
\hline
\end{tabular}

a Solvent, toluene, $4 \mathrm{ml}$.

b Total monomer, $7.0 \mathrm{mmol}$.

c Total monomer, $10.6 \mathrm{mmol}$.

d Total monomer, $11.0 \mathrm{mmol}$.

e $[\eta], \mathrm{dl} \mathrm{g}^{-1}$ at $30^{\circ} \mathrm{C}$ in DMF. 
and isolation of copolymer were carried out by a procedure similar to that of free radical polymerization. Yield $1.18 \mathrm{~g}(62.0 \%)$.

\section{Measurements}

The NMR spectrum was measured by a $60 \mathrm{MHz}$ JNM-PMX60 NMR spectrometer at $35^{\circ} \mathrm{C}$. The IR spectrum was taken with a HITACHI-EPI-S2 type spectrometer. Molecular weights were determined on a Hitachi Perkin-Elmer 115 vapor pressure osmometer. The intrinsic viscosity of the polymer was measured in a dimethylformamide solution by an Ubbelohde-type viscometer at $30 \pm 0.05^{\circ} \mathrm{C}$.

\section{Flame Resistance}

The flame resistance was evaluated by a modification of JIS K6705-1972. Test polymer pieces $(10 \mathrm{~mm} \times 10 \mathrm{~mm} \times 10 \mathrm{~mm})$ were prepared by casting of molten polymers followed by cooling. It was pierced with a hole of $1.6 \mathrm{~mm}$ in diameter at the center of the face. An electric wire of $1.4 \mathrm{~mm}$ in diameter was passed through the hole, and was maintained horizontally. An electric current was turned on, and the electric power of consumption was maintained at $70 \mathrm{~W}$ per $100 \mathrm{~mm}$ length and continued for ten minutes, and then stopped. After the electric current was turned on, the time until the polymer was ignited and the flame-continuing time after stopping the current were measured.

\section{RESULTS AND DISCUSSION}

Synthesis of Monomers

Monomers were synthesized by the following steps (Scheme I).

Dry conditions were necessary, because $p$ vinylphenol is reactive to give poly(hydroxystyrene) with a trace of acid. The Crude yield was essentially quantitative by the NMR method, although the isolated yield was sometimes considerably low as described in the experimental part because of losses incured during the distillation necessary for obtaining a pure product.

\section{Free Radical and Cationic Homopolymerization}

The polymerization conditions and the results of the polymerization are summarized in Table I. The polymerization of PO, PS or TS was carried out in solution or in bulk. Glassy and transparent polymers were obtained. The molecular weight of polymer was independent of the polymerization conditions and was not so high in either the free radical or the cationic polymerization. This was due perhaps to the presence of inhibiting groups such as a trace of $p$ vinylphenol or sulfur group in the monomer. It is well known that some sulfur-containing compounds inhibit a peroxide-catalyzed polymerization. However, the molecular weight of polymers derived from radical polymerization was a little high in comparison with that of polymers cationically polymerized.

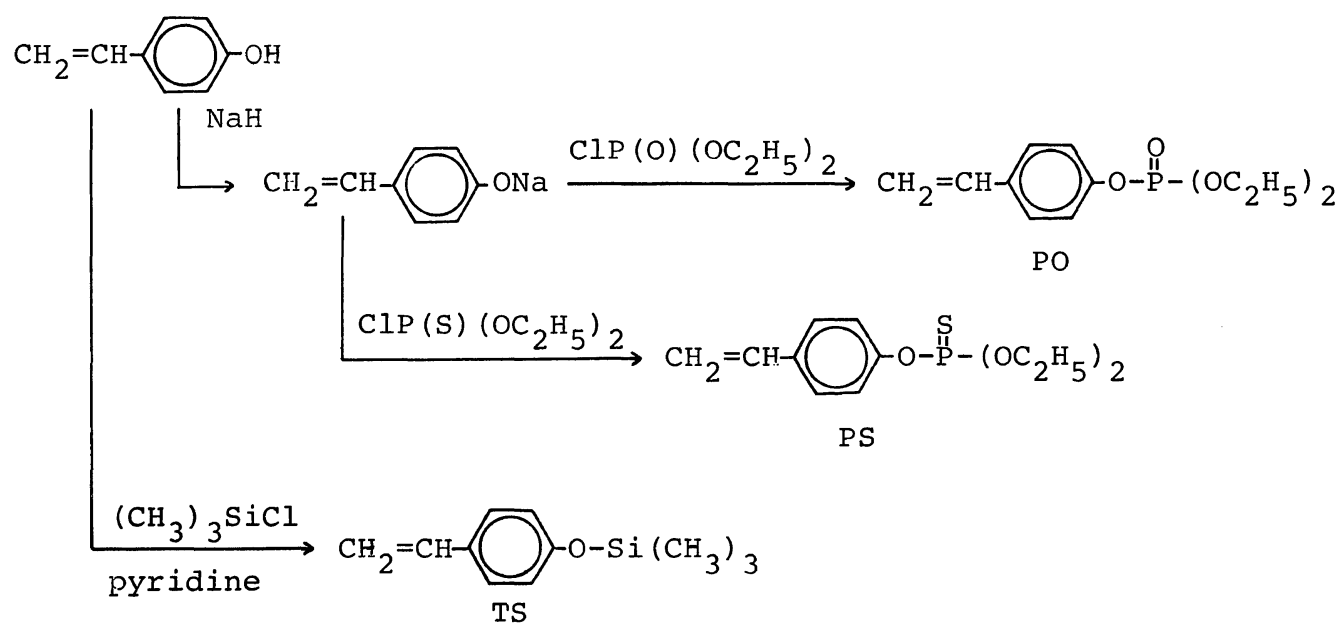

Scheme I 
In the cationic polymerization of $\mathrm{TS}$, the product was varied with the concentration of $\mathrm{BF}_{3} \mathrm{OEt}_{2}$. At a high catalyst concentration, poly(hydroxystyrene) was produced by the hydrolysis of oxygen-silicon bond with acid. By using less than $0.1 \mathrm{~mol} \%$ of $\mathrm{BF}_{3} \mathrm{OEt}_{2}$ based on TS, poly(TS) was obtained.

\section{Copolymerization}

Copolymerization conditions and the results of the polymerization are listed in Table II. Copolymerizations of PS, PO or TS with MMA, ST, Manh or MA were carried out using AIBN as an initiator. Transparent and colorless copolymers were produced in each case. Also, the molecular weights were not so high. However, the melting points of the copolymers were somewhat higher than those of homopolymers. The rate of copolymerization for PO or PS with Manh appeared significantly faster than that for PO or PS with MMA, ST or MA. The molecular weight of PO-Manh or PS-Manh copolymer was fairly high. From these results, it was found that PO or PS have high copolymerizability.

The relationship between the monomer and copolymer composition is indicated in Figures 3-5. The copolymer yield was kept below $10 \%$ in each case. The copolymer compositions were calculated from the results of NMR spectrum and the elementary analysis. Alternating copolymers were obtained in the copolymerization of PO or PS with Manh. The alternating tendency of PO or PS is greater in copolymerization with MMA than in that with ST, as expected. The monomer reactivity ratios evaluated by the Fineman-Ross method and $Q-e$ values proposed by Alfrey and Price are

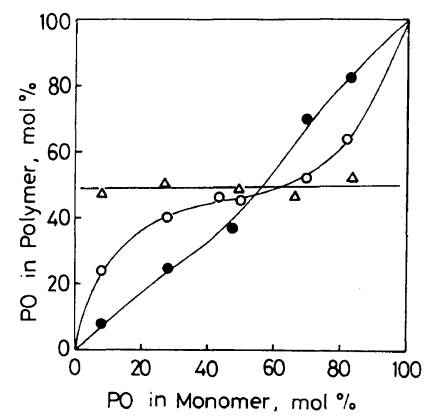

Figure 3. Copolymer compositions of $\mathrm{PO}$ in relation to monomer composition at $60^{\circ} \mathrm{C}: \mathrm{O}, \mathrm{PO}-\mathrm{MMA}$;, $\mathrm{PO}-$ ST; $\triangle$, PO-Manh; total feed monomer, $1 \mathrm{mmol} \mathrm{ml}^{-1}$ in toluene; AIBN, $0.1 \mathrm{~mol} \%$ with respect to feed monomers.

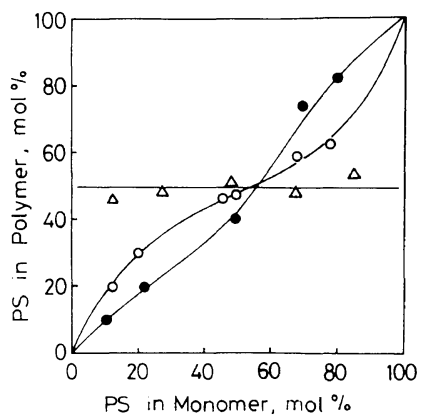

Figure 4. Copolymer compositions of $\mathrm{PS}$ in relation to monomer composition at $60^{\circ} \mathrm{C}$ : $\bigcirc$, PS-MMA; ST; $\triangle$, PS-Manh; total feed monomer; $1 \mathrm{mmol} \mathrm{ml}^{-1}$ in toluene; AIBN, $0.1 \mathrm{~mol} \%$ with respect to feed monomers.

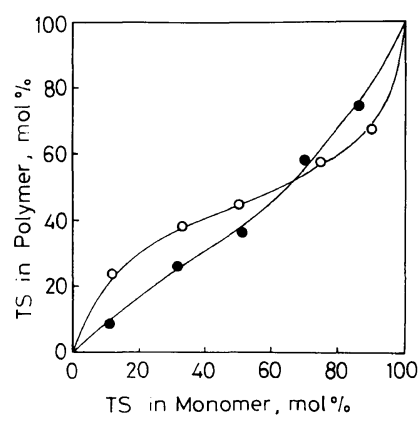

Figure 5. Copolymer compositions of TS in relation to monomer composition at $60^{\circ} \mathrm{C}$ : $\mathrm{O}$, TS-MMA; $\bigcirc$, TSST; total feed monomer, $1 \mathrm{mmol} \mathrm{ml}^{-1}$ in toluene; AIBN, $0.1 \mathrm{~mol} \%$ with respect to feed monomers.

shown in Table III.

The $e_{1}$-value or the polarity factor of PO, PS or TS is more negative than it is for $p$-methoxystyrene $(-1.11) .{ }^{13}$ Among these values, the $e_{1}$-value for TS was rather close to that for $p$-methoxystyrene. It is generally accepted that styrene derivatives substituted with an electron-donating group in the ortho or para position have a more negative $e$-value than styrene itself and give an alternating copolymer with an electron-acceptor monomer such as Manh.

The resonance term $Q_{1}$ for PO or PS was higher than that for $p$-methoxystyrene (1.36). On the other hand, $Q_{1}$ for TS was somewhat smaller than that for $p$-methoxystyrene. However, the $Q_{1}$ value is influenced by the comonomer to a small extent.

\section{Flame Resistance}

Many polymers of organic phosphonates are of 
Table III. Monomer reactivity ratios $r_{1}, r_{2}$, and $Q-e$ values ${ }^{\mathrm{a}}$ for PS, PO, and TS at $60^{\circ} \mathrm{C}$ by AIBN in toluene

\begin{tabular}{clccccc}
\hline $\mathrm{M}_{1}$ & $\mathrm{M}_{2}$ & $r_{1}$ & $r_{2}$ & $r_{1} \times r_{2}$ & $e_{1}$ & $Q_{1}$ \\
\hline \multirow{2}{*}{ PS } & MMA & 0.25 & 0.25 & 0.063 & -1.26 & 1.50 \\
& ST & 1.15 & 1.10 & 1.27 & & \\
PO & MMA & 0.20 & 0.20 & 0.04 & -1.39 & 1.78 \\
& ST & 1.05 & 1.25 & 1.31 & -1.19 & 0.98 \\
TS & MMA & 0.20 & 0.40 & 0.08 & -1.23 & 0.93 \\
& ST & 0.55 & 1.50 & 0.83 & \\
\hline
\end{tabular}

a ST, $e=0.80, Q=1.00$; MMA, $e=0.40, Q=0.74$. Refer to G. E. Ham, Ed., "Copolymerization," Interscience, New York, N.Y., 1964.

the self-extinguishing type. It has been assumed that this high flame resistance is due to the presence of the phosphorus atom. Table IV lists the flame resistance evaluated by the JIS K6705-1972 method for a simple mixture of PO or PS polymer and polyethylene or poly(methyl methacrylate), and copolymers of PO or PS with MMA, MA or ST, along with the calculated values for the phsophorus contents of polymers.
It is obvious from these data that flame resistance is more effective in the polymers containing phosphorus-oxygen than phosphorus-sulfur, while the flame was soon extinguished in the PS type copolymers and the flame was not widely extended by electrical reheating. Polymers containing phosphorus-oxygen were not burnt and were chared independent of such conditions as simple blend or copolymers. Also, there was no direct correlation-

Table IV. Flame resistance ${ }^{a}$

\begin{tabular}{|c|c|c|c|}
\hline \multirow{3}{*}{ Sample ${ }^{b}$} & \multirow{3}{*}{$\frac{\text { Ignition delay time }}{\mathrm{c}}$} & \multirow{3}{*}{$\begin{array}{l}\begin{array}{c}\text { Flame-continuing } \\
\text { time }\end{array} \\
\frac{\mathrm{s}}{\mathrm{time}}\end{array}$} & \multirow{3}{*}{$\begin{array}{c}\mathrm{P} \\
\mathrm{wt} \%\end{array}$} \\
\hline & & & \\
\hline & & & \\
\hline Poly(MMA) & 20 & 120 & 0 \\
\hline Copoly(PS-MMA) & 50 & Soon extinguished & 5 \\
\hline Copoly(PO-MMA) & No ignition & Charred & 5 \\
\hline Poly(MA) & 17 & 120 & 0 \\
\hline Copoly(PS-MA) & 80 & Soon extinguished & 4 \\
\hline Copoly(PO-MA) & No ignition & Charred & 4 \\
\hline $\operatorname{Poly}(\mathrm{ST})$ & 48 & 120 & 0 \\
\hline Copoly(PS-ST) & 80 & Soon extinguished & 4 \\
\hline Copoly(PS-ST) & No ignition & Charred & 4 \\
\hline $\operatorname{Poly}(E)$ & 30 & 150 & 0 \\
\hline Poly(PS) + Poly(E) & No ignition & Charred & 1 \\
\hline $\operatorname{Poly}(\mathrm{PO})+\operatorname{Poly}(\mathrm{E})$ & No ignition & Charred & 1 \\
\hline Poly (PS $)+\operatorname{Poly}($ MMA $)$ & No ignition & Charred & 1 \\
\hline Poly $(\mathrm{PO})+\operatorname{Poly}(\mathrm{MMA})$ & No ignition & Charred & 1 \\
\hline
\end{tabular}

a The flame resistance was evaluated by the modification of JIS K6705-1972.

b Poly(MMA), poly(methyl methacrylate); Poly(MA), poly(methyl acrylate); Poly(ST), polystyrene; Poly(E), polyethylene.

c The time until the polymer was ignited.

d The flame-continuing time after stopping the current. 
ship between the phosphorus content and flame resistance as reported previously. ${ }^{8}{ }^{8}$ However, it is noteworthy that the flame resistance of simple blend of polyethylene or poly(methyl methacrylate) with homopolymer of PO or PS seems to be slightly higher than that of copolymers, indicating that an aggregate state of the phosphorus groups may induce a high flame resistance.

Consequently, mixtures of phosphoruscontaining homopolymer and the flammable polymer are excellent from the point of flame resistance, but the phosphorus-containing copolymers have a miscibility with the flammable polymers and show superiority in processability for a polymer blend.

\section{REFERENCES}

1. H. A. Schuyten, J. W. Weaver, and J. D. Reid, Ind.
Eng. Chem., 47, 1433 (1955).

2. Chem. Eng. News, 35, No. 37, 6 (1957).

3. M. I. Kabachnik, Izv. Akad. Nauk SSSR, Otdel. Khim. Nauk, 233 (1947).

4. A. N. Nesmeyanov, I. F. Lutsenko, Z. S. Kraits, and A. P. Bokovoi, Dokl. Akad. Nauk SSSR, 124, 1251 (1959).

5. G. M. Kosolapoff, J. Am. Chem. Soc., 70, 1971 (1948).

6. A. D. F. Toy and L. Broun, U.S. Patent 2586885 (1952); Chem. Abstr., 46, 5888 (1952).

7. T. C. Baker, U.S. Patent 2680105 (1954); Chem. Abstr., 48, 11110 (1954).

8. A. D. F. Toy, J. Am. Chem. Soc., 70, 186 (1948).

9. A. D. F. Toy and R. S. Cooper, J. Am. Chem. Soc., 76, 2191 (1954).

10. W. J. Dale, J. Am. Chem. Soc., 80, 3645 (1958).

11. T. H. Siddall and C. A. Prohaska, J. Am. Chem. Soc., 84, 3467 (1962).

12. M. Kato, J. Polym. Sci., A-1, 7, 2405 (1969).

13. L. J. Young, J. Polym. Sci., 54, 411 (1961). 